\title{
DIPTERA FROM THE MESILLA VALLEY OF THE RIO GRANDE IN NEW MEXICO. - II.
}

BY C. H. TYLER TOWNSEND, LAS CRUCES, N. MEXICO.

The present section of this paper is to record what appears to be the growing occurrence in the Mesilla Valley, in southern New Mexico, of species belonging to the tachinid subfamilies Phasiidae, Gymnosomatidae, and Ocypteridae. As pointed out in section I, Gymnosoma was not known in New Mexico previous to $\mathrm{r} 894$, the only representatives of the above groups known before then being several hyalomyiid forms (belonging in the Phasiidae). Since I894, Gymnosoma has turned up more commonly; and in 1897 both Ocyptera and, what is more remarkable, Trichopoda have been discovered for the first time in New Mexico. These occurrences are very interesting from a biogeographical point of view, and indicate the probable future occurrence and discovery in the Mesilla Valley not only of Cistogaster (which is allied to Gymnosoma), but also of Xanthomelanodes, a member of the Phaniidae, which is the remaining one of the four small primordial groups of Tachinidae. The flies of these groups are, as a rule (excepting the hyalomyiid flies), inhabitants of low moist regions in temperate and tropical latitudes. Their occurrence in the Mesilla Valley points to a spread of these forms from lower moister regions up the valley of the Rio Grande into New Mexico.
PHASIIDAE.

3. Trichopoda histrio var. indivisa Towns. One male, Sept. 3, and two females, August 25 and Sept. 2, on flowers of Solidago canadensis, on the acequia banks within the town of Las Cruces, all collected by myself in 1897 . These are the first and only specimens of Trichopoda known from within the boundaries of New Mexico, and their discovery calls for an amendment of my statement on page 279 of the Annals and Magazine of Natural History (London), series 6, vol. xx, Sept. I897.

The female differs from the male, aside from the claw and frontal characters, in the second segment being without golden pollen, while the third is golden pollinose except the wide anterior and posterior margins. The male has the third to sixth segments wholly golden pollinose; while the second segment is yellowish except narrow anterior and posterior margins, but not distinctly pollinose. The coloring of the wings is quite the same in both sexes. The male front at vertex is hardly twice as wide as the distance between the two posterior ocelli; while that of female is twice or two and one-half times as wide as this distance. The third and fourth segments of male, and fourth segment of 
female, are narrowly brown on hind margin, showing the incisures.

It will be seen, by comparing descriptions, that the present specimens have (at least in the male) more golden pollen on abdomen than the San Rafael (Vera Cruz) specimen, thus indicating a tendency toward still another variety.

\section{GYMNOSOMATIDAE.}

(9) Gymnosoma fuliginosa Desv. One male, August 3I; and three females, August 30 and Sept. 3; all on flowers of Solidago canadensis on acequia banks within the town of Las Cruces, taken by the writer in 1897 . The number of specimens previously taken in New Mexico is seven.

\section{OCYPTERIDAE.}

(го) Ocyptera euchenor Walk. One male, August 3I ; and one female, Sept. 2 ; both on flowers of Solidago canadensis on acequia banks within the town of Las Cruces, taken by the writer in i 897. Length, ro to $1 \circ \frac{1}{2} \mathrm{~mm}$. These are additional to the specimen taken by
Cockerell, August 5, 1897, on flowers of Bigelovia wrightii in the Mesilla Valley, and already recorded (Psyche, Dec., r 897, pp. r49-r 50).

Mr. D. W. Coquillett, in his " Revision of Tachinidae," calls this species $O$. carolinae Desv. I have no copy of Desvoidy's Myodaires at hand to verify this reference.

I4. Ocyptera euchenor var. dosiades Walk. One female, August 25, on flowers of Clematis ligusticifolia, on acequia banks within the town of Las Cruces, taken by the writer in 1897 . Length, $7 \mathrm{~mm}$.

This is not the dosiades of Mr. D. W. Coquillett, in his "Revision of Tachinidae," as it has the two pairs of marginal macrochaetae, as well as the smaller apical pair. It is the form which I have heretofore always referred to dosiades Walk. When Mr. Coquillett adduces some evidence to show that Walker's types of dosiades possessed no apical pair of bristles, and but one marginal pair, I will revise the present determination.

\section{DESCRIPTION OF AN UNUSUAL SAW-FLY LARVA BELONGING TO THE XYELINAE.}

BY HARRISON G. DYAR, WASHINGTON, D. C.

As far as I can ascertain there is no description extant of any larva of the subfamily Xyelinae of the Tenthredinidae. Cameron says in his monograph that the larvae are without feet, and
Dalla Torre in his catalogue gives a note stating that Xyela julii lives on Betula alba, but without reference to any description.

In the vicinity of New York there has 

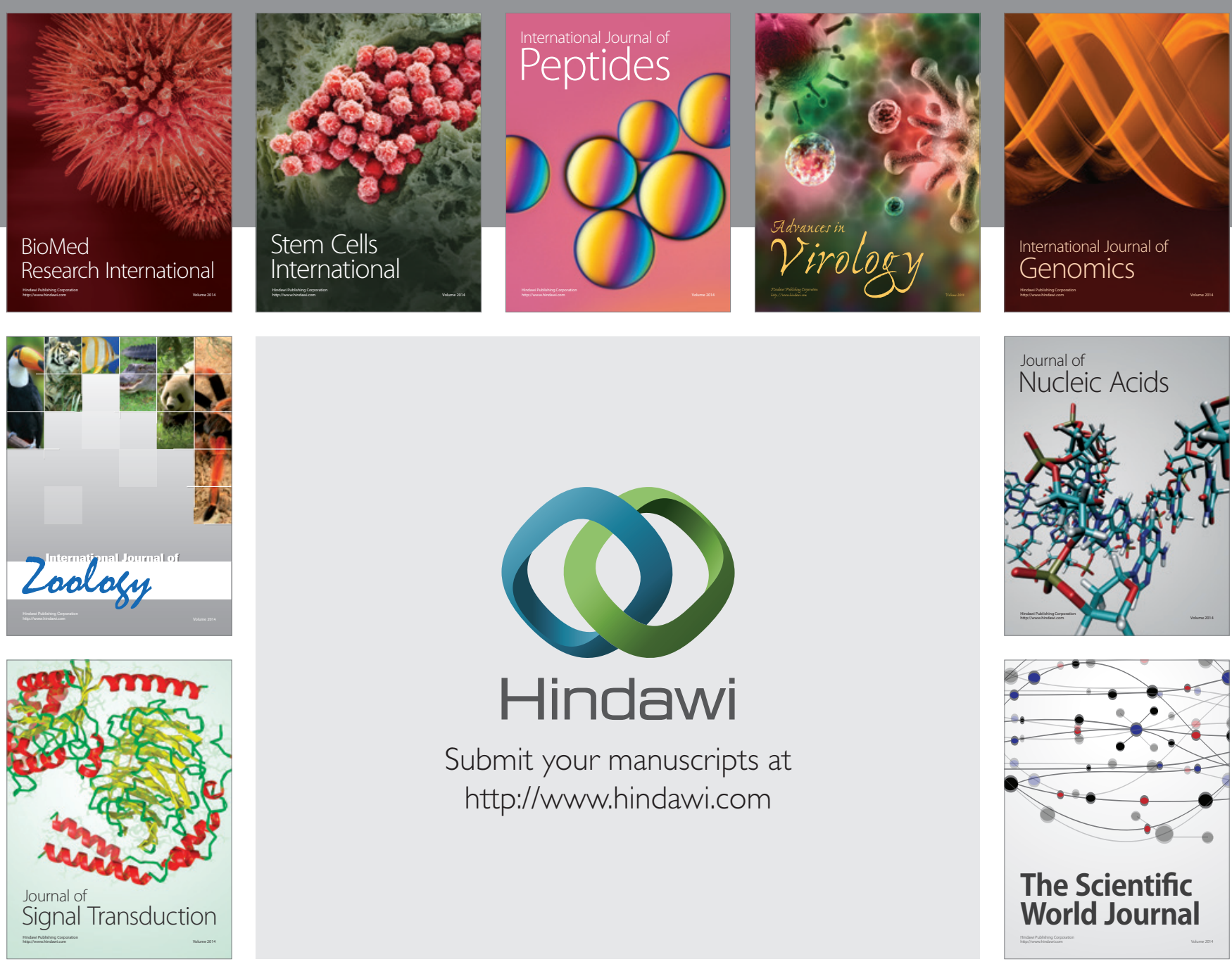

Submit your manuscripts at

http://www.hindawi.com
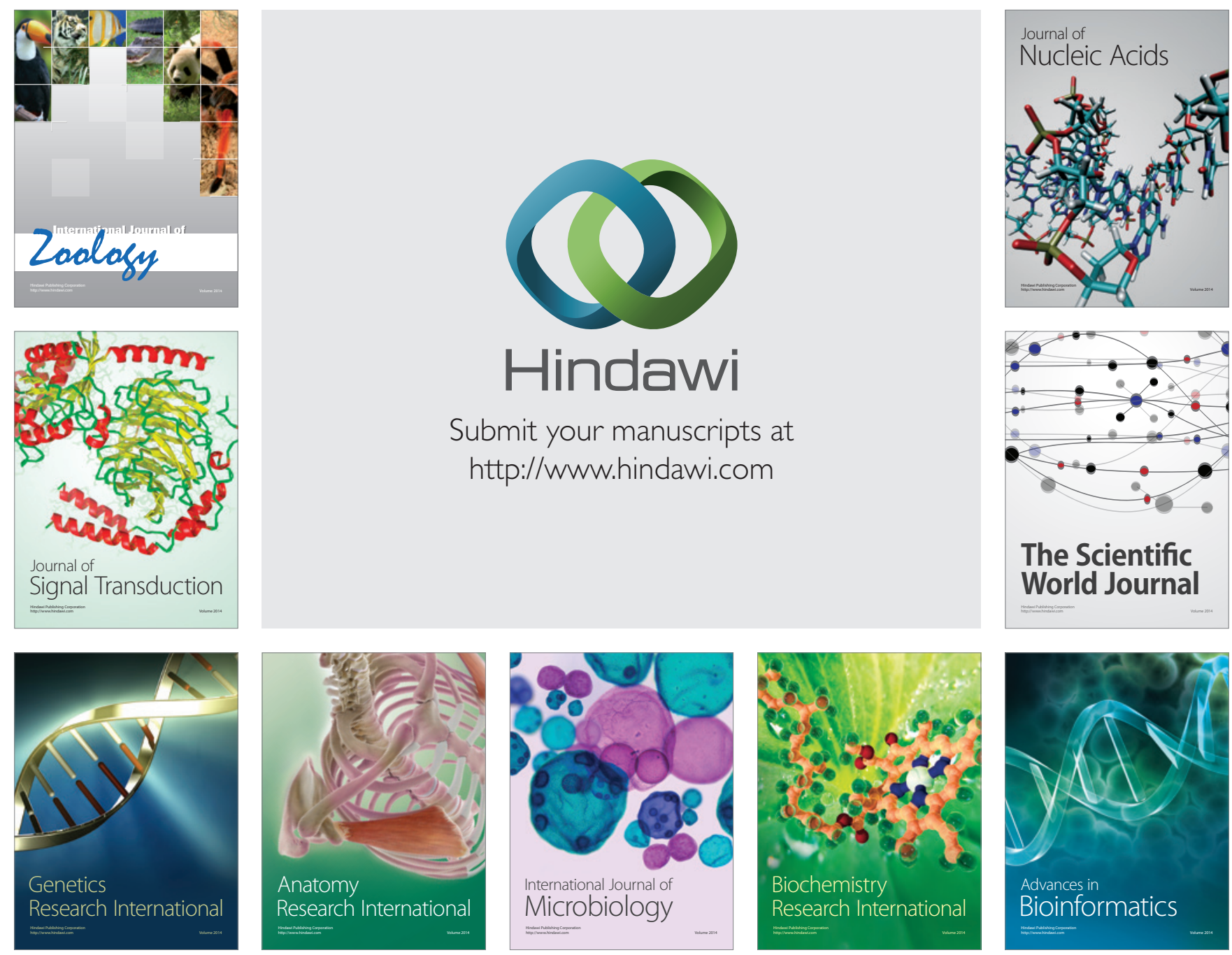

The Scientific World Journal
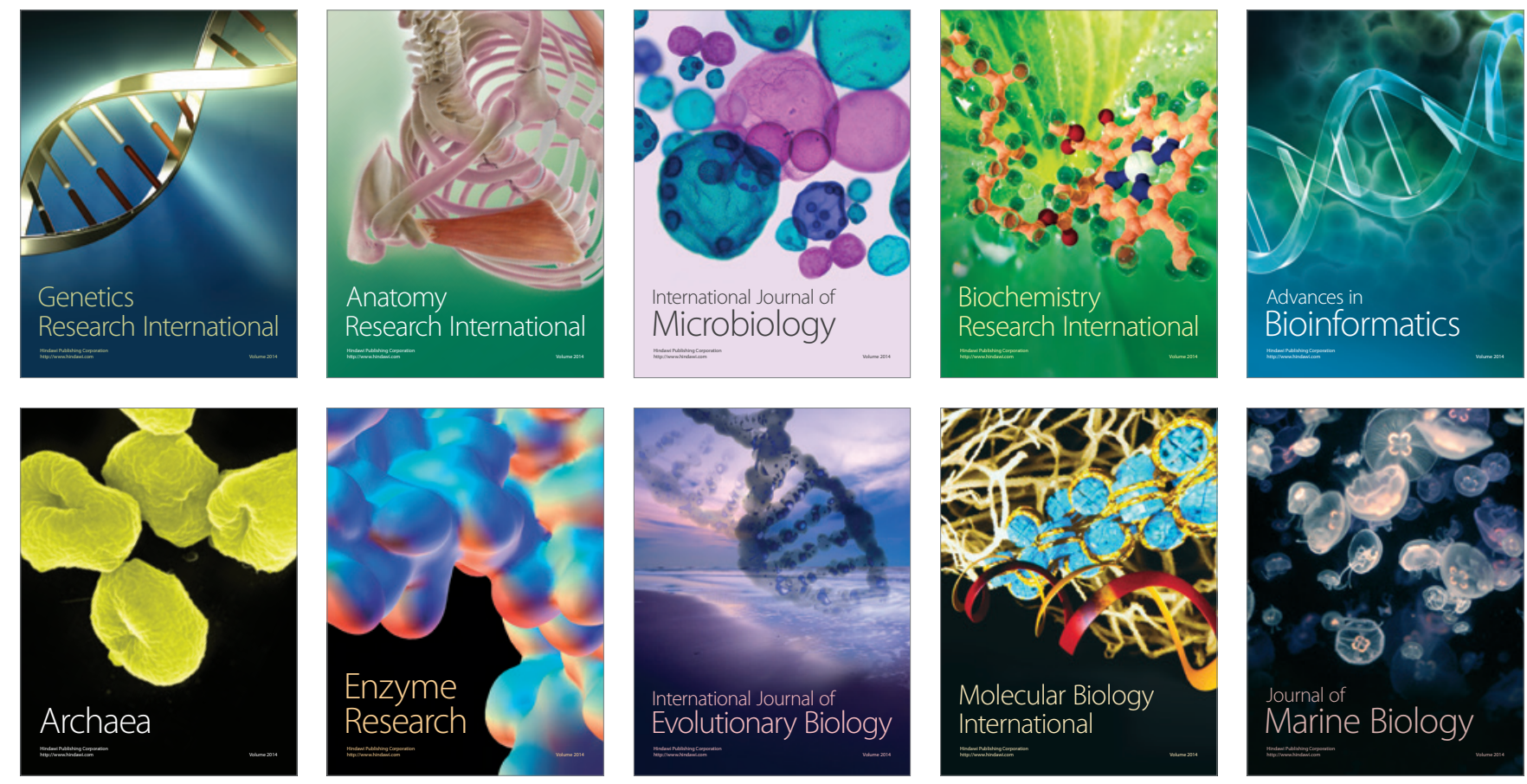